\title{
Marine Biology: A Sub-Sample of a Vast Topic
}

\author{
Laurent Seuront ${ }^{1,2,3}$ \\ ${ }^{1}$ CNRS UMR 8187 LOG, Université de Lille-Sciences et Technologies, Station Marine, Wimereux, France \\ ${ }^{2}$ School of Biological Sciences, Flinders University, Adelaide, Australia \\ ${ }^{3}$ South Australian Research and Development Institute, Aquatic Sciences, West Beach, Australia \\ Email: laurent.seuront@univ-lille1.fr, laurent.seuront@flinders.edu.au
}

Copyright (C) 2013 Laurent Seuront. This is an open access article distributed under the Creative Commons Attribution License, which permits unrestricted use, distribution, and reproduction in any medium, provided the original work is properly cited.

\section{1. "Marine Biology", the First Special Issue of the Open Journal of Marine Science}

Since the origin of life in the primordial ocean, the marine environment has developed into a vast variety of habitats in both the coastal and open waters of the world ocean. Coastal waters are home of a range of transition zones between the sea, freshwater and land, such as intertidal muddy, sandy and rocky shores, mangrove and saltmarshes, estuaries, kelp forests, seagrass meadows and coral reefs. The open ocean comprises the wellknown epipelagic zone, i.e. the upper 100 - 200 meters of the open ocean fueled by solar radiations and photosynthesis, where plethora of marine life is concentrated, and the still drastically unexplored deep-sea habitats that rely on vertical fluxes of organic matter from the surface.

Marine organisms ranging from minute microbes to large fish, seabirds and mammals have colonized all of these habitats. Reflecting this great diversity in living conditions and selective forces, aquatic organisms have evolved a corresponding diversity of forms (Figure 1), life history patterns, physiological and biological adaptations, and reproductive and behavioral strategies. Understanding the biology of these various organisms becomes especially important in an era of global change where anthropogenic and climatic stressors (e.g. organic and mineral contaminants, temperature, $\mathrm{pH}$ ) are increasingly threatening marine habitats.

Marine biology is undeniably vast topic. Despite its limited length, this special issue compiles seven papers that reflect this diversity and cover diverse aspects of the biology of marine organisms ranging from invertebrates such as flagellates [1], corals [2,3] and krill [4], to vertebrates such as waders [5] and dolphins [6], and also addresses more fundamental questions related to the actual relevance and future of benthic indicators [7]. All of the papers briefly described hereafter introduce new insights into the biology of their target organisms, and it is hoped that the reader will enjoy the salty taste of this sub-sample of such a vast topic, Marine Biology.

\section{The Diatom-Eager Benthic Flagellate}

Heterotrophic nanoflagellates have typically been considered as grazers of heterotrophic bacteria [8], hence trophically distinct from herbivorous protists like ciliates and dinoflagellates $[9,10]$. Following recent studies describing heterotrophic nanoflagellates feeding on diatoms much larger than themselves [11-13], Ohno et al. [1] describe the trophic biology and growth of a diatomfeeding flagellate (Figure 2) recently discovered in the bottom sediment of Onagawa Bay, Japan [14]. Based on laboratory incubations, Ohno et al. [1] demonstrate that

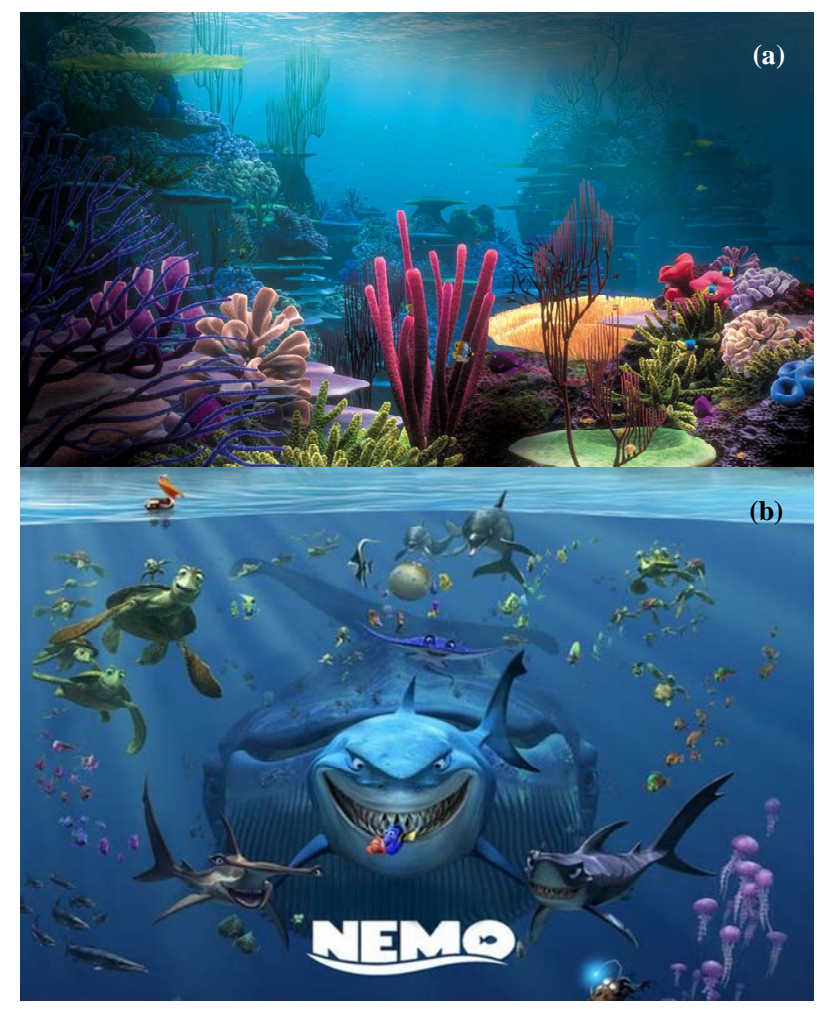

Figure 1. The diversity of benthic (a) and pelagic (b) life forms found in the world ocean, as illustrated in the blockbuster computer-animated film "Finding Nemo". (c) 2003 Disney/Pixar. 


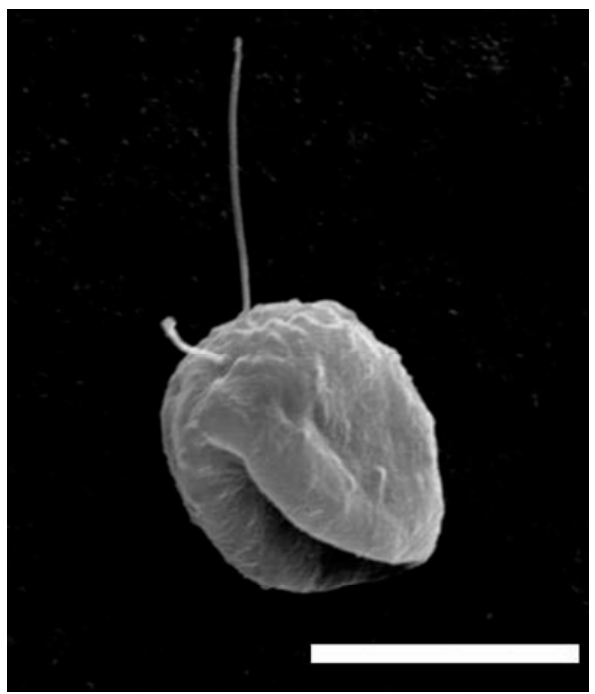

Figure 2. Scanning electron micrograph of the Skeletonema costatum-feeding flagellate described by Ohno et al. [1]. Scale bar: $9 \mu \mathrm{m}$.

flagellates are able to remove up to $25.6 \%$ of the sinking flux of the diatom Skeletonema coastatum in Onagawa Bay. This suggests that diatom-feeding flagellates may have a significant impact on diatom dynamics and play an important, though overlooked, role in benthos-pelagos coupling.

\section{Does UV-B Radiation Matter More than Visible Light in the Physiological Response and Survival of the Deep Coral Stylophora pistillata?}

Both the quality and the quantity of light play a critical role in the survival of all photosynthetic organisms in the photic zone [15]. While the exposure of deep-water corals to high UV-B levels in shallower water is usually fatal, Cohen et al. [2] investigate the effect of the PAR/ UV-B ratio on the physiological response and the survival of the deep-water coral Stylophora pistillata (Figure 3) through 1) a in situ stepwise, acclimatization of $S$. pistillata from their original depth $(30 \mathrm{~m})$ to shallow waters $(3 \mathrm{~m})$, i.e. a progressive decrease in PAR/UV-B ratio, and 2) shaded ex situ incubations of coral fragments from the same colonies under conditions of constant PAR/UVB ratio. In both experiments, all S. pistillata fragments survived despite drastic changes in both PAR levels and UV-B fluxes between initial and final conditions, i.e. 4and 140-fold differences in PAR level and UV-B flux. The resulting changes in zooxantellae density, maximum photosynthetic rate, and the quantum yield of PSII led to the conclusion that the oxidative stress caused by UV-B may serve as a signal for corals to enhance acclimation rate while PAR increases. This new aspects of photoac-

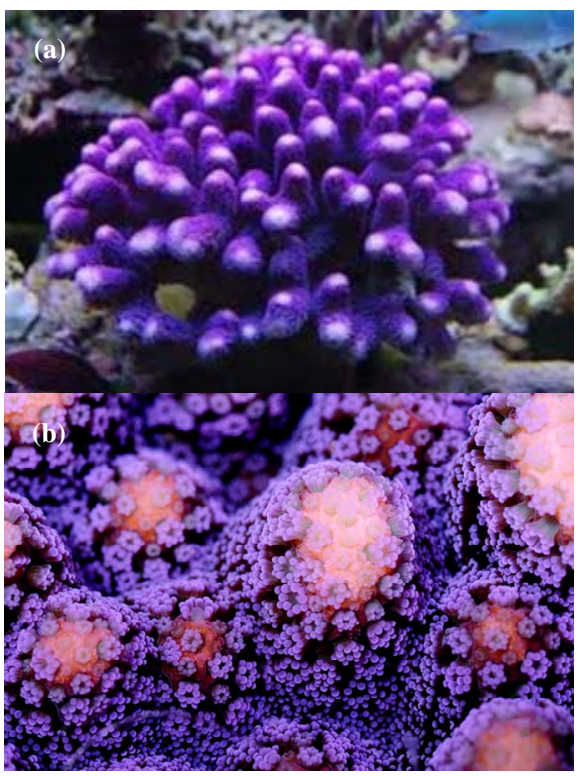

Figure 3. The deep coral Stylophora pistillata, general (a) and close-up (b). Credit: Tim Wijgerde.

climatation is critical as it may provide a stepping-stone to further our understanding of the underlying mechanisms that result in UV-related bleaching events [16]. More generally, a better understanding of the effects of solar UV radiation on aquatic ecosystems is particularly relevant in the actual era of global change [17].

\section{Resistance and Resilience of Coral Assemblages to Temperature Anomalies: Implications for Conservation}

Elevated sea surface temperature anomalies have widely been associated with coral bleaching and mortality worldwide [18-23]. In this context, Foster et al. [3] describe the coral communities othroughout the southeastern Arabian Gulf ten years after the recurrent elevated temperature anomalies (ETA) observed in 1996, 1998 and 2002 that led to mass mortality of Acropora spp (Figure 4). The coral communities assessed from 2006 to 2009 were compared to the communities found before and after the three ETAs. Specifically, massive corals (e.g. Porites spp. and faviids) showed no long-terms affects associated with exposures to the three thermal anomalies. In contrast, acroporids that comprise up to $8 \%$ of the live coral cover were in various stages of recovery.

A number of scenarios based on combinations of actual and idealized numbers of recruits per year, and negative and/or positive growth further suggests that acroporid would require up to 32 years to reach their predisturbance coverage. Note, however, that because the actual acroporid communities are still too small in size and density to be self-seeding, their potential route to full recovery rely on the recruitment of larvae from alloch- 


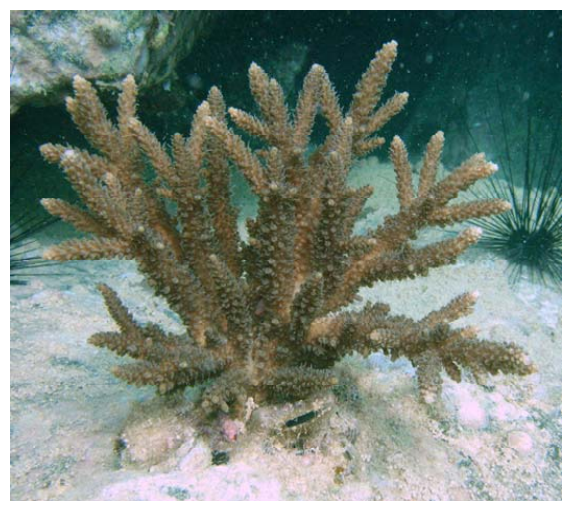

(a)

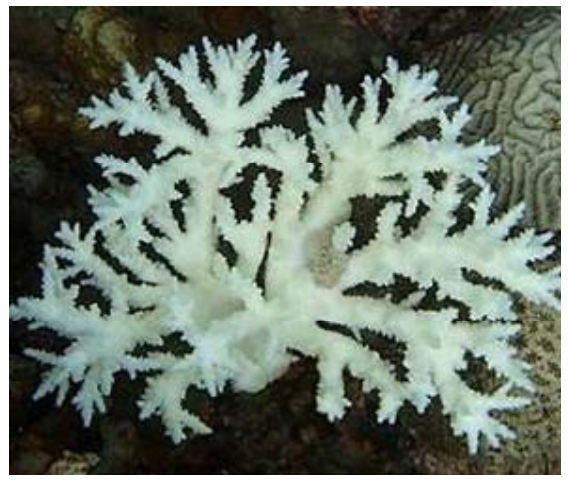

(b)

Figure 4. Healthy (a) and bleached (b) Acropora sp. Coralfrom the Arabian Gulf bleachedduringsummer 2012. Credit: Keith Wilson (a) and Coral Reef Laboratory (b).

thonous communities that survived, already recovered or were minimally impacted by the thermal anomalies. Hence, as stated by Foster et al. [3] "connectivity is key" to recovery.

However, the projected regeneration times exceed the intervals between disturbances, which are, in turn, expected to occur more frequently as a result of global climate change [24]. This is a very serious threat for the future of acroporid corals in the Arabian Gulf. From a conservation standpoint, the key to recovery intrinsically lies in the establishment of multi-national cooperation programs between Iran, Abu Dhabi, Dubai, Saudi Arabia and Kuwait to identify and protect areas where acroporids survived previous thermal anomalies, and determine the potential connectivity between coral communities. This is the absolute pre-requisite to optimize the subsistence of actual acroporid corals, and to assess their chances to act as a seed bank throughout the Arabian Gulf. Note that the transplantations of coral fragments to areas impacted by thermal anomalies, though shown to be effective [25], are limited to the native thermal limits of the transplanted species [26]. It is then stressed that no coral conservation strategy will be effective until underlying intrinsic and/or extrinsic factors driving high mor- tality rates are understood and mitigated or eliminated.

\section{Exogenous, but Also Endogenous, Forces Drive the Metabolic Rates of Antarctic Krill, Euphausia superba}

Despite their economic and ecological importance in the pelagic realm of the Southern Ocean, the Antarctic krill (Euphausia superba; Figure 5), and the relative strategies developed to survive or avoid periods of starvation (i.e. overall body shrinkage and protein catabolism, utilization of lipid reserves, switching to a more omnivorous and/or carnivorous diet, as well as feeding on ice-algae and sea-floor detritus, and suppression of metabolism), our understanding of krill metabolism as a response to their fluctuating environment is still limited. Based on the recent claim that an endogenous circannual timing mechanism is operating in krill and controls their physicology and behavior, and that photoperiod is probably acting as their main driver [27], Brown et al. [4] assessed krill metabolism through long-term incubations under different light, food and temperature conditions. They particularly focus on the critical period of maturation in late winter/early spring and sexual regression in late summer/early autumn. Their results suggest that light, food availability and temperature all significantly affect krill metabolic rate. Noticeably, no significant relationship was found between krill total length and metabolism.

The most relevant finding of this study may be related to the evidence for a seasonal pattern of winter lowsummer high metabolic rates. This suggests that krill metabolic rates might be driven by endogenous rather than exogenous factors, hence supports previous hypothesis of the existence of a krill internal clock that controls the overall seasonal pattern of krill metabolic activity [27,28]. Brown et al. [4] finally advocate the need for even longer term experiments that would investigate

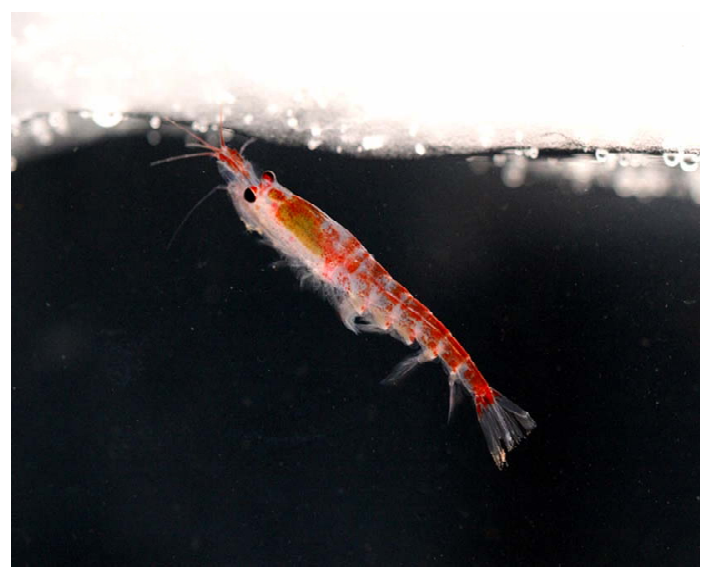

Figure 5. The Antarctic krill Euphausia superba swimming under ice. Credit: Dr. Jan van Franeker, IMARES. 
the role of photoperiod in dictating internal processes and incorporate metabolic rate measurements over more than an annual cycle to be able to assess a possible unsynchronization between the above-mentioned internal clock and a perfect annual cycle.

\section{Is the Macrozoobenthos Present in the Sediment Actually Available to Waders?}

This may at first sound like a silly question. It is, however, a fundamental issue (though widely overlooked!), to deepen our understanding of the functioning of food webs in intertidal soft-sediment. More specifically, standard approaches used to assess macrobenthos abundance and community composition are based on sediment cores sampled at depths varying from 15 to $40 \mathrm{~cm}$; see e.g. [29] for a review. The related information, though ecologically valuable, are useless in terms of assessing their potential role in the trophodynamics of waders as these shorebirds can only feed upon preys that are within reach of the bill [30]. Luczak et al. [5] used this simple fact as the stepping stone for the development of a new core sampler that allows to relate directly the vertical distribution of macrozoobenthos to waders bill length; bill lengths are used as a proxy of probing depth to estimate the amount of food supply accessible. This new device uniquely allows to cut a sediment core at different depths defined a priori depending on the shorebirds (hence the length of their bill) under consideration to determine the fraction of the macrozoobenthos that is actually available to a given species. Luczak et al. [5] subsequently illustrate the performance of their device in a real life case study conducted during an annual wader survey (19992000) in the Canche estuary (northwest France), where five species-Sanderling (Calidris alba; Figure 6), Dunlin (Calidris alpina), Curlew (Numenius arquata), Oystercatcher (Haematopus ostralegus) and Ringed Plover (Charadrius dubius) - dominate the waders population and represent more than $97.5 \%$ of their total abundance.

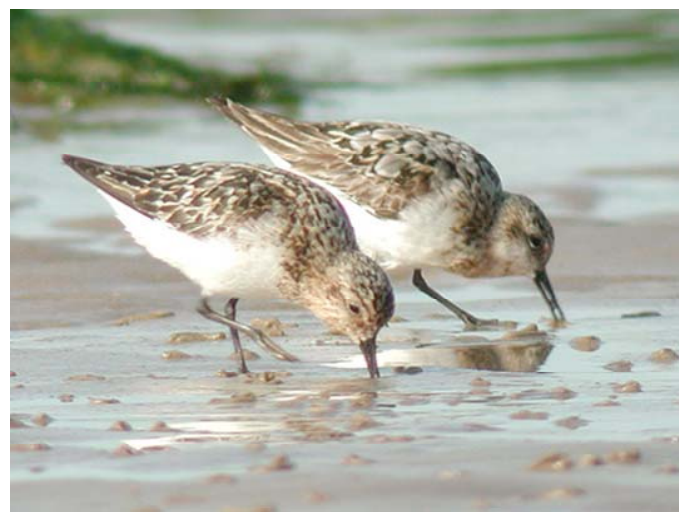

Figure 6. The Sanderling Calidris alba probing in the sand for macrozoobenthos. Credit: C. Rolland.
Through a thorough survey of the bill measurements available in the literature for the main species of coastal waders in northwestern Europe, Luczak et al. [5] critically discussed the need to include a range of bill lengths in any study meant to assess the macrozoobenthic preys accessible to waders. They discuss the relevance of their sampling device to assess the vertical distribution of macrozoobenthos and their fraction actually available to waders. Luczak et al. [5] also stress that sediment corer can conveniently be used to assess the physical structure of benthic habitats (texture, vertical stratification, mean depth of apparent Redox Potential Discontinuity), hence to build a Benthic Habitat Quality index sensu Nilsson \& Rosenberg [31]. As such, their new multilevel sediment corer goes well beyond traditional benthic sampling strategies, and its versatility makes it applicable in virtually any aquatic ecosystem.

\section{New Insights into the Population Status of an Elusive Marine Mammal, the Risso's Dolphins (Grampus griseus) in Wales Waters}

Despite a nearly circum global distribution, the Risso's dolphins Grampus griseus (Figure 7) belongs to those marine mammal species that are still relatively unknown, essentially because they are relatively shy, difficult to approach and as deep divers they often disappear underwater for long periods of time [32]. Only a few abundance estimates exists outside European waters [33], hence the yield of both opportunistic and systematic sightings data is not sufficient to allow reliable abundance assessment.

Because Risso's dolphins typically exhibit long-lasting identifiable natural marks, which include distinctive nicks in their dorsal fins, patterns of scarring and variations in dorsal fin shape (Figure 7), photo-identification techniques can be used to study association patterns and social structure for this species [34]. Hence, based on systematic line-transect surveys off Bardsley Island (Cardigan Bay, Wales), and opportunistic boat surveys lauched during dedicated land-based observations, de Boer et al. [6] compiled photo-identification data from eight summers (1997-2007) and find that the dolphins show a degree of long-term and seasonal site-fidelity, and identify a long-distance match $(319 \mathrm{~km})$ between Bardsey Island and Cornwall, confirming they can be wide-ranging animals as previously shown in the Mediterranean Sea (164 km [35]) and the Gulf of Mexico (3300 km [36]). Additionally, de Boer et al. [6] confirm the regular presence of Risso's dolphins in these waters, provide the first local abundance for Risso's dolphins in UK waters, and the presence of calves shows breeding. Besides, it is suggested that Bardsey Island may be part 


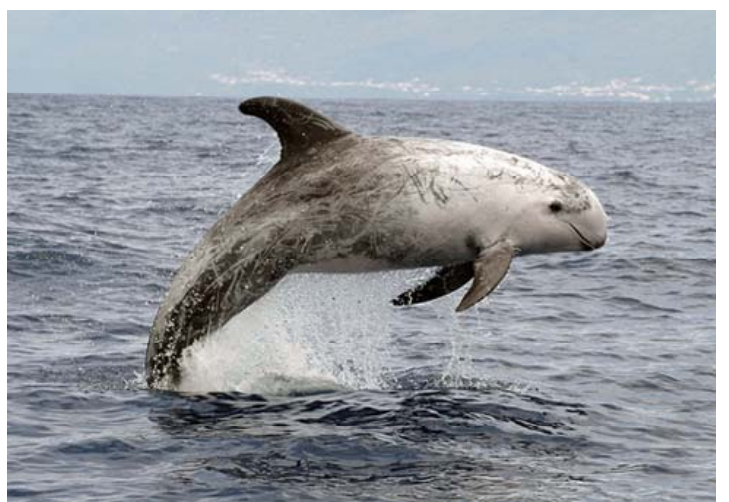

Figure 7. A Risso's dolphin Grampus griseus breaching. Credit: Nova Atlantis Foundation.

of a network of localities that are important habitats to this species where it may take advantage of prey abundance in shallow waters, as recently suggested for other species, e.g. the Indo-Pacific bottlenose dolphin (Tursiops aduncus) in coastal urbanized environments [37].

de Boer et al. [6] further discuss the limitations of their approach, which are likely to affect any study of elusive species such as Risso's dolphin, if not all marine mammal species. In particular, the shape of the discovery curve indicates that the population had not yet been sufficiently sampled even after 11 years of study. While this may be related to the transient nature of Risso's dophins that appear annually in the study area, this also stresses that a proper assessment of their population status and trends need a shorter temporal periodicity, and a higher sample effort per year. Overall this study illustrates the benefits of combining systematic and opportunistic photoidentification studies and their complementary value as a population assessment tool in generating the first local abundance estimate for Risso's dolphins in UK waters.

\section{Are Benthic Indicators a Threatened Species?}

In this short review, Spilmont [7] shows that the use of benthic indicators has drastically increased over the last decades. In particular, the number of articles published on this topic, as well as the number of citations, has been increasing since the early 90 's, in relation with the implementation of directives for the management of aquatic/marine ecosystems such as the Water Framework Directive and the Marine Strategy Framework Directive. Spilmont [7] further argues that current benthic indicators suffer from severe drawbacks and their practical use is still discussed (Figure 8(a)), hence might have reached a dead end.

Specifically, in [7], Table 1 identifies-non-exhaustively but critically - five major drawbacks of current benthic indicators:

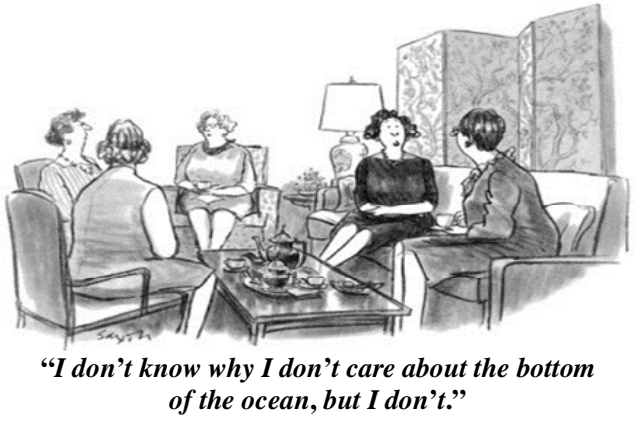

(a)

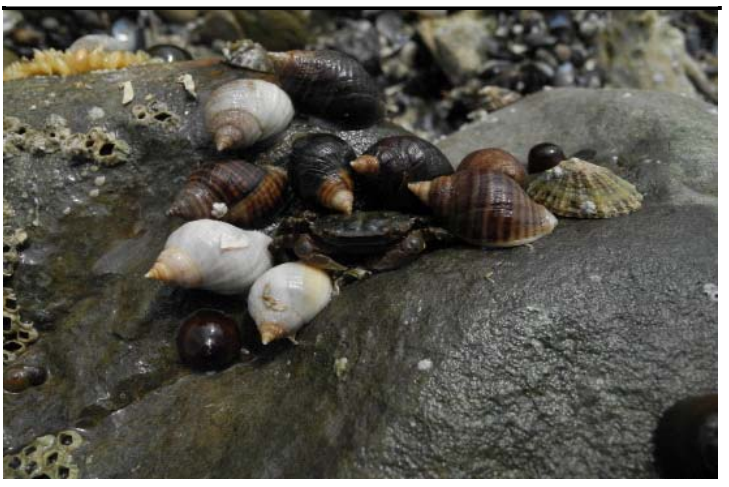

(b)

Figure 8. A caricatural, somehow cynical, potential view of the perception of benthic environments and indicators (a) and (b) an illustration of the potential of intertidal ecosystems (here the rocky shore of the Fort de Croy, Wimereux, France) for the development of benthic indicators through e.g. easy and cost effective observations as shown by the invasive crab Hemigrapsus sanguineus hidden in a patch of native species including the dog whelk Nucella lapillus (note the different phenotypes), the beadlet anemone Actinia equina, and the common limpet Patella vulgata (Credit: Charles Saxon (a) and Dr. N. Spilmont (b).

1) Expert-dependence: $58 \%$ of the samples examined by experts from Europe and USA differ in their ecological classification [38];

2) Methodological-dependence: differences in sampling methods and sieving methods respectively led to differences in the ecological classification of $28 \%$ to $48 \%$ and $17 \%$ to $83 \%$ (sic) of the stations analyzed [39,40];

3) Inconsistency between indicators: the ecological classification of $74 \%$ of the stations examined differ depending on the indicator [41], while five different biotic indicators diverge on the status of $65 \%$ to $90 \%$ of the stations investigated [42];

4) Temporal variability: the ecological classification of a station differ at the seasonal scale [43];

5) Operational limits: the ecological classifications provided by both the BOPA and the BOPA2 indexes are based on differences on their $5^{\text {th }}$ digits $[44,45]$, e.g. station characterized by BOPA $=0.13965$ and 0.13967 will have good and moderate ecological status, respectively. 
In short, Spilmont [7] demonstrates that indicators based on species composition are far from satisfactory, because e.g. they exhibit a high space-time variability and minor changes even when communities are disturbed, and are user-dependent as shown from the divergent results obtained by US or Europe experts from the same samples. In contrast, changes in behavior, metabolic rates, phenotypic or stable isotopes compositions can be observed in impacted areas, even if the community structure (e.g. abundance, diversity) remains unchanged, and occur at relatively short time scales, especially when compared to detectable changes in community composition, and makes their use particularly relevant as indicators of perturbation. For example, behavioral analyses have the potential to be used as an "early warning" signals to assess the status of marine environments [46].

The paper finally advocates that intertidal ecosystems, through 1) their keystone ecological position as a land/ sea and air/water interface and primary importance to assess the impact of human activities and global warming on marine ecosystems; 2) their accessibility and the subsequent relatively easy and cost efficient observations (Figure 8(b)) and manipulative experiments; 3) the everincreasing number of studies assessing intertidal structure and function since the early 80's; and 4) the predicted high cumulated impacts of human activities in areas where anthropogenic disturbances (both direct and indirect) are manifest, are an excellent candidate for the development of new benthic indicators. Besides, potential functional benthic indicators are plethora in the intertidal, and have the desirable advantage to be easy and quick to implement, hence represent an effective alternative to current benthic indicators.

\section{REFERENCES}

[1] H. Ohno, Y. Endo, W. Sato-Okoshi and G. Nishitani, "Feeding and Growth Characteristics of a Diatom-Feeding Flagellate Isolated from the Bottom Sediment of Onagawa Bay, Northeastern Japan," Open Journal of Marine Science, Vol. 3, No. 2A, 2013, pp. 9-14.

[2] I. Cohen, G. Dishon, D. Iluz and Z. Dubinsky, "UV-B as a Photoacclimatory Enhancer of the Hermatypic Coral Stylophora pistillata," Open Journal of Marine Science, Vol. 3, No. 2A, 2013, pp. 15-27.

[3] K. A. Foster, G. Foster and S. Al-Harthi, "Coral Assemblages in the Southeastern Arabian Gulf (Qatar and Abu Dhabi, UAE): Various Stages of Acropora Recovery a Decade after Recurrent Elevated Temperature Anomalies," Open Journal of Marine Science, Vol. 3, No. 2A, 2013, pp. 28-39.

[4] M. Brown, S. Kawaguchi, S. Candy, T. Yoshida, P. Virtue and S. Nicol, "Long-Term Effect of Photoperiod, Temperature and Feeding Regimes on the Respiration Rates of Antarctic Krill (Euphausia superba)," Open Journal of Marine Science, Vol. 3, No. 2A, 2013, pp. 40-51.
[5] C. Luczak, D. Menu and C. Rolet, "A Multilevel Core Sampler Device to Directly Estimate Food Supply Accessible to Waders," Open Journal of Marine Science, Vol. 3, No. 2A, 2013, pp. 52-64.

[6] M. N. de Boer, J. Clark, M. F. Leoplod, M. P. Simmonds and P. J. H. Rejinders, "Photo-Identification Methods Reveal Seasonal and Long-Term Site-Fidelity of Risso's Dolphins (Grampus griseus) in Shallow Waters (Cardigan Bay, Wales)," Open Journal of Marine Science, Vol. 3, No. 2A, 2013, pp. 65-74.

[7] N. Spilmont, "The Future of Benthic Indicators: Moving up to the Intertidal," Open Journal of Marine Science, Vol. 3, No. 2A, 2013, pp. 75-85.

[8] E. B. Sherr, B. F. Sherr and J. McDaniel, "Clearance Rates of $<6 \mu \mathrm{m}$ Fluorescently Labeled Algae (FLA) by Estuarine Protozoa: Potential Grazing Impact of Flagellates and Ciliates," Marine Ecology Progress Series, Vol. 69, No. 1, 1991, pp. 81-92. doi:10.3354/meps069081

[9] E. B. Sherr and B. F. Sherr, "Capacity of Herbivorous Protists to Control Initiation and Development of Mass Phytoplankton Blooms," Aquatic Microbial Ecology, Vol. 57, No. 3, 2009, pp. 253-262. doi:10.3354/ame01358

[10] E. B. Sherr and B. F. Sherr, "Heterotrophic Dinoflagellates: A Significant Component of MicrozooplanktonBioMass and Major Grazers of Diatoms in the Sea," Marine Ecology Progress Series, Vol. 352, 2007, pp. 187 197. doi:10.3354/meps07161

[11] G. Drebes, S. F. Kühn, A. Gmelch and E. Schnepf, "Cryothecomonasae stivalis sp. nov., a Colourless Nanoflagellate Feeding on the Marine Centric Diatom Guinardia delicatula (Cleve) Hasle," Helgoländer Meeresunters, Vol. 50, No. 4, 1996, pp. 497-515. doi:10.1007/BF02367163

[12] S. Kühn, L. Medlin and G. Eller, "Phylogenetic Position of the Parasitoid Nanoflagellate Pirsonia Inferred from Nuclear-Encoded Small Subunit Ribosomal DNA and Description of Pseudopirsonia n. gen. and Pseudopirsonia mucosa (Drebes) comb. nov.," Protist, Vol. 155, No. 2, 2004, pp. 143-156. doi:10.1078/143446104774199556

[13] E. Schnepf and S. F. Kühn, "Food Uptake and Fine Structure of Cryothecomonas longipes spec. nov., a Marine Nanoflagellate Incertae sedis f Feding Phagotrophically on Large Diatoms," Helgoland Marine Research, Vol. 54, No. 1, 2000, pp. 18-32. doi: $10.1007 / \mathrm{s} 101520050032$

[14] Y. Masuda, "Pelagic and Benthic Microbial Food Webs in Onagawa Bay," Ph. D Thesis, Tohoku University, Sendai, 2008. (in Japanese)

[15] J. T. O. Kirk, "Light and Photosynthesis in Aquatic Ecosystems," Cambridge University Press, Cambridge, 2010. doi:10.1017/CBO9781139168212

[16] D. F. Gleason and G. M. Wellington, "Ultraviolet-Radiation and Coral Bleaching," Nature, Vol. 365, No. 6449, 1993, pp. 836-838. doi:10.1038/365836a0

[17] D. P. Häder, H. D. Kumar, R. C. Smith and R. C. Worrest, "Effects of Solar UV Radiation on Aquatic Ecosystems and Interactions with Climate Change," Photochemicaland Photobiological Science, Vol. 6, 2007, pp. 267-285. doi:10.1039/b700020k 
[18] C. Wilkinson, "Status of Coral Reefs of the World: 1998," Australian Institute of Marine Science, Townsville, 1998.

[19] T. Goreau, T. McClanahan, R. Hayes and A. Strong, "Conservation of Coral Reefs after the 1998 Global Bleaching Event," Conservation Biology, Vol. 14, No. 1, 2000, pp. 5-15. doi:10.1046/j.1523-1739.2000.00011.x

[20] C. Wilkinson, "Status of the Coral Reefs of the World: 2000," Australian Institute of Marine Science, Townsville, 2000.

[21] J. F. Bruno, C. Siddon, J. D. Whitman, P. L. Colin and M. A. Toscano, "El Niño Related Coral Bleaching in Palau, Western Caroline Islands," CoralReefs, Vol. 20, No. 2, 2001, pp. 127-136. doi:10.1007/s003380100151

[22] P. J. Mumby, J. R. M. Chisholm, A. J. Edwards, C. D. Clark, E. B. Roark, S. Andrefouet and J. Jaubert, "Unprecedented Bleaching-Induced Mortality in Porites spp. at Rangiron Atoll, French Polynesia," Marine Biology, Vol. 139, No. 1, 2001, pp. 183-189. doi: $10.1007 / \mathrm{s} 002270100575$

[23] R. B. Aronson, W. F. Precht, M. A. Toscano and K. H. Koltes, "The 1998 Bleaching Event and Its After-Math on a Coral Reef in Belize," Marine Biology, Vol. 141, No. 3, 2002, pp. 435-447. doi:10.1007/s00227-002-0842-5

[24] Intergovernmental Panel on Climate Change (IPCC), "Climate Change 2007: The Physical Science Basis," In: S. Solomon, D. Qin, M. Manning, Z. Chen, M. Marquis, K. B. Averyt, M. Tignor, H. L. Miller, Eds., Contribution of Working Group I to the Fourth Assessment Report of the Intergovernmental Panel on Climate Change, Cambridge University Press, Cambridge, 2007.

[25] V. H. Garrison and G. Ward, "Transplantation of StormGenerated Coral Fragments to Enhance Carribean Coral Reefs: A Successful Method but not a Solution," Revista de Biologia Tropical, Vol. 60, No. Suppl. 1, 2012, pp. 5970 .

[26] E. J. Howells, R. Berkelmans, M. J. H. van Oppen, B. L. Willis and L. K. Bay, "Historical Thermal Regime Define Limits to Coral Acclimatization," Ecology, Vol. 94, No. 5, 2013, pp. 1078-1088. doi:10.1890/12-1257.1

[27] B. Meyer, "The Overwintering of Antarctic Krill, Euphausia superba, from an Ecophysiological Perspective," Polar Biology, Vol. 35, No. 1, 2012, pp. 15-37. doi:10.1007/s00300-011-1120-0

[28] W. Hagen, "Reproductive Strategies and Energetic Adaptations of Polar Zooplankton," Invertebrate Reproduction and Development, Vol. 36, No. 1-3, 1999, pp. 25-34. doi:10.1080/07924259.1999.9652674

[29] T. Piersma, P. De Goeij and I. Tulp, "An Evaluation of Intertidal Feeding Habitats from Shorebird Perspective: Towards Relevant Comparisons between Temperate and Tropical Mudflats," Netherland Journal of Sea Research, Vol. 31, 1993, pp. 503-512. doi:10.1016/0077-7579(93)90062-W

[30] L. Zwarts and J. H. Wanink, "The Macrobenthos Fraction Accessible to Waders May Represent Marginal Prey," Oecologia, Vol. 87, No. 4, 1991, pp. 581-587. doi:10.1007/BF00320424

[31] H. C. Nilsson and R. Rosenberg, "Benthic Quality As- sessment of an Oxygen Stressed Fjord by Surface and Sediment Profile Images," Journal of Marine Systems, Vol. 11, No. 3-4, 1997, pp. 249-264. doi:10.1016/S0924-7963(96)00111-X

[32] R. W. Baird, W. F., Perrin, B. Wursig and J. G. Thewissen, "Encyclopedia of Marine Mammals," Academic Press, Burlington, 2009.

[33] G. Bearzi, R. R. Reeves, E. Remonato, N. Pierantonio and S. Airoldi, "Risso's Dolphin Grampus griseus in the Mediterranean Sea," Mammal Biology, Vol. 76, No. 4, 2010, pp. 385-400. doi:10.1016/j.mambio.2010.06.003

[34] K. L. Hartman, F. Visser and A. Hendriks, "Social Structure of Risso's Dolphins at the Azores: A Stratified Community Based on Highly Associated Social Units," Canadian Journal of Zoology, Vol. 86, No. 4, 2008, pp. 294 306. doi:10.1139/Z07-138

[35] N. David and L. Di Méglio, "First Results of Summer Movements of Grampus griseus (Cuvier, 1812) in the Mediterranean Sea," European Research Cetaceans, Vol. 13, 1999, pp. 189-194.

[36] R. S. Wells, C. A. Manire, L. Byrd, D. R. Smith, J. G. Gannon, D. Fauquier and K. Mullin, "Movements and Dive Patterns of a Rehabilitated Risso's Dolphin, Grampus griseus, in the Gulf of Mexico and Atlantic Ocean," Marine Mammal Science, Vol. 25, No. 2, 2009, pp. 420429. doi:10.1111/j.1748-7692.2008.00251.x

[37] N. Cribb, C. Miller and L. Seuront, "Indo-Pacific Bottlenose Dolphin (Tursiopsaduncus) Habitat Preference in a Heterogeneous, Urban, Coastal Environment," Aquatic Biosystems, Vol. 9, No. 1, 2013, p. 3. doi:10.1186/2046-9063-9-3

[38] H. Teixeira, A. Borja, S. B. Weisberg, J. A. Ranasinghe, D. B. Cadien, D. M. Dauer, J.-C. Dauvin, S. Degraer, R. J. Diaz, A. Grémare, I. Karakassis, R. J. Llansó, L. L. Lovell, J. C. Marques, D. E. Montagne, A. Occhipinti-Ambrogi, R. Rosenberg, R. Sardá, L. C. Schaffner and R. G. Velarde, "Assessing Coastal Benthic Macrofauna Community Condition Using Best Professional JudgementDeveloping Consensus Across North America and Europe," Marine Pollution Bulletin, Vol. 60, No. 4, 2010, pp. 589-600. doi:10.1016/j.marpolbul.2009.11.005

[39] R. Pinto, J. Patricio, A. Baeta, B. D. Fath, J. M. Neto and J. C. Marques, "Review and Evaluation of Estuarine Biotic Indices to Assess Benthic Condition," Ecological Indicators, Vol. 9, No. 1, 2009, pp. 1-25. doi:10.1016/i.ecolind.2008.01.005

[40] I. Karakassis, P. D. Dimitriou, N. Papageorgiou, E. T. Apostolaki, N. Lampadariou and K. D. Black, "Methodological Considerations on the Coastal and Transitional Benthic Indicators Proposed for the Water Framework Directive," Ecological Indicators, Vol. 29, 2013, pp. 2633. doi:10.1016/j.ecolind.2012.12.020

[41] R. Simonini, V. Grandi, G. Massamba-N'Siala, M. Lotti, G. Montarani and D. Prevedelli, "Assessing the Ecological Status of North-Western Adriatic Sea within the European Framework Directive: A Comparison of Bentix, AMBI and M-AMBI Methods," Marine Ecology, Vol. 30, No. 2, 2009, pp. 241-254. doi:10.1111/j.1439-0485.2009.00281.x 
[42] H. Blanchet, N. Lavesque, T. Ruellet, J.-C. Dauvin, P.-G. Sauriau, N. Desroy, C. Desclaux, M. Leconte, G. Bachelet, A.-L. Janson, C. Bessineton, S. Duhamel, J. Jourde, S. Mayot, S. Simon and X. de Montaudouin, "Use of Biotic Indices in Semi-Enclosed Coastal Ecosystems and Transitional Waters Habitats-Implications for the Implementation of the European Water Framework Directive," Ecological Indicators, Vol. 8, No. 4, 2008, pp. 360372. doi:10.1016/j.ecolind.2007.04.003

[43] H. Reiss and I. Kröncke, "Seasonal Variability of Benthic Indices: An Approach to Test the Applicability of Different Indices for Ecosystem Quality Assessment," Marine Pollution Bulletin, Vol. 50, No. 12, 2005, pp. 1490-1499. doi:10.1016/j.marpolbul.2005.06.017

[44] J.-C. Dauvin and T. Ruellet, "Polychaete/Amphipod Ra- tio Revisited," Marine Pollution Bulletin, Vol. 55, No. 1-6, 2007, pp. 215-224.

doi:10.1016/j.marpolbul.2006.08.045

[45] J.-C. Dauvin and T. Ruellet, "The Estuarine Quality Paradox: Is It Possible to Define an Ecological Quality Status for Specific Modified and Naturally Stressed Estuarine Ecosystems?" Marine Pollution Bulletin, Vol. 59, No. 1-3, 2009, pp. 38-47. doi:10.1016/j.marpolbul.2008.11.008

[46] J. Hellou, "Behavioural Ecotoxicology, an 'Early Warning' Signal to Assess Environmental Quality," Environmental Science and Pollution Research, Vol. 18, No. 1, 2011, pp. 1-11. doi:10.1007/s11356-010-0367-2 